\title{
NEW INITIATIVES IN ELECTRONICS
}

\author{
North Carolina's Microelectronics Center Is An Innovative \\ Model Of How Government, Industry, And University Can Work Together \\ To Advance Research. An Integrated National Effort, However, Remains To Be Made.
}

\author{
BY DONALD S. BEILMAN \\ President, \\ Microelectronics Center of North Carolina
}

Advances in technology have never been taking place at a more rapid pace. No field has felt the impact of technological progress any more than modern electronics, including microelectronics and its uses, and this field holds much more promise for the future.

Not only is modern electronics a major expanding industry which has experienced phenomenal growth, but it also contributes directly to modernization and productivity improvement in basic industries. In addition, advances in modern electronics are essential to maintaining U.S. leadership in defense and national security programs.

The size of the modern electronics market, as well as its importance, has created intense international competition. Western European nations and Japan have launched major national efforts to challenge the United States leadership in modern electronics and related technologies.

The presence and importance of this challenge has been well documented in our professional journals as well as the general press. The question that still remains unanswered, however, is whether or not the U.S. will remain cast in the leading role or will Europe or Japan possibly dominate the electronics industry.

This answer depends upon many factors. Not the least of these is our willingness to embrace change. And not just technological change. We as a nation are very effective in managing scientific progress. Rather, a more fundamental change ... in how we seek technological advances, nourish them through development, and translate them into competitive goods and services. In short, radically altering how we manage technology transfer and innovation.

In the Last Tycoon, F. Scott Fitzgerald wrote: "There are no second acts in American lives." If his wry observation is correct-about us as individuals, and our country as a whole-we will get older, but not wiser. We will hew to the old approaches, relying on staid institutions and tired management concepts. Meanwhile, other nations, tailoring novel strategies to new realities, will pass us by.

However, I believe Fitzgerald's observation is wide of the mark. I think the U.S. can continue to have a starring part for itself as higher technology microelectronics ushers in the Industrial Revolution's second act.

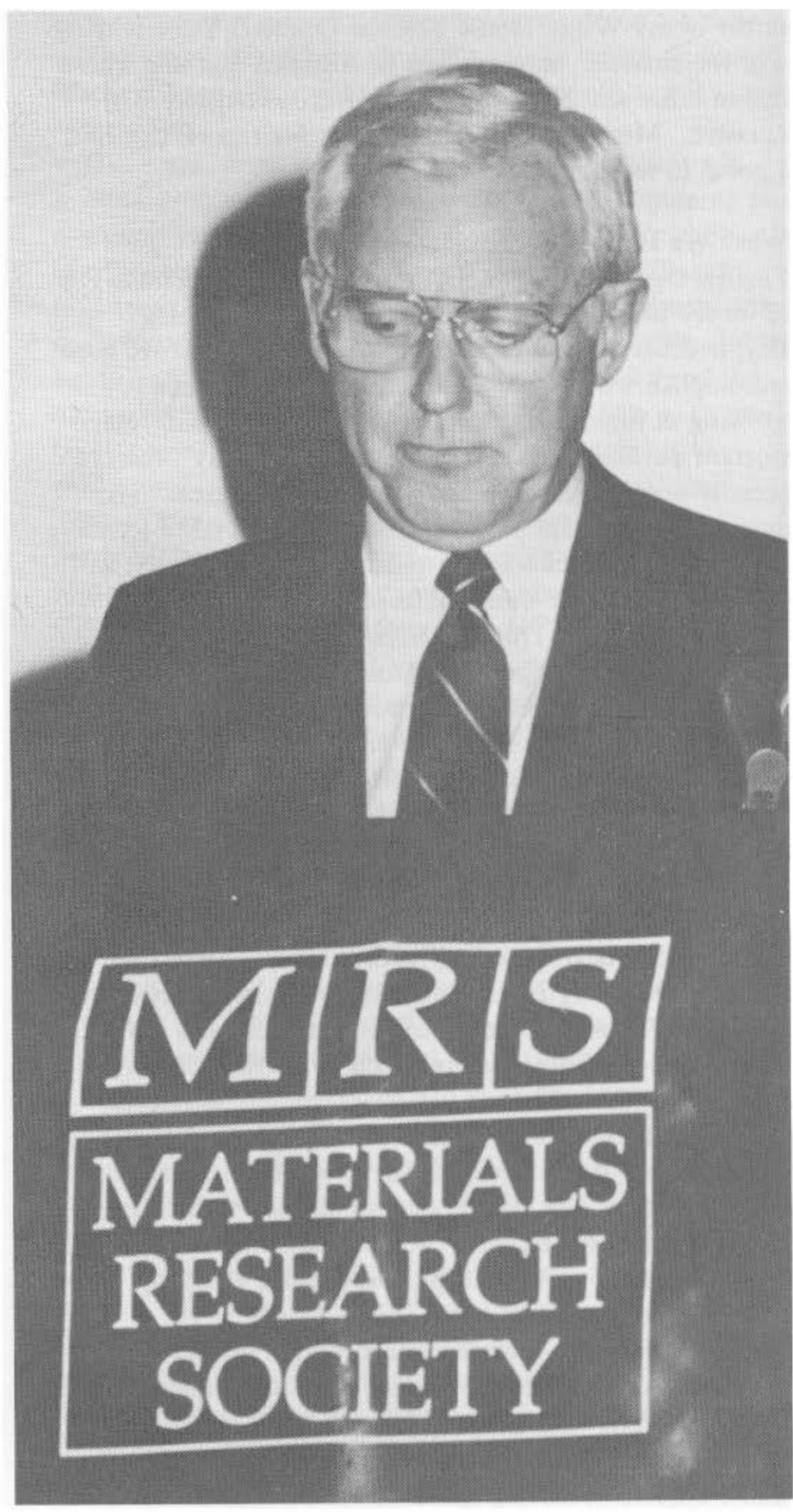

DONALD BEILMAN 
But we must look within the U.S. at our own institutions and leaders to forge the bold new initiatives that will establish innovative coalitions. Ones that unite business, universities, and government.

A national initiative such as Japan's MITI is probably neither likely nor workable in the U.S. What we need are responses that recognize our own strengths versus current world realities. A uniquely American approach. An approach that builds on the investments that have already been made; that recognizes the flexibility of decentralization but also recognizes the need for coordination-not only at the local level but also at the national level. An approach compatible with our democratic philosophy and free enterprise system.

The outline of this American approach is beginning to emerge and it is this approach that I would like to comment on today.

\section{Realities}

First, there are some key realities.

The approach that the U.S. takes in response to foreign challenges is limited by available resources. That includes financial resources as well as the availability of top notch professional talent which, while abundant at this conference, is limited overall.

Rapid advances in technology such as those we are experiencing in modern electronics also create additional pressures on both available financial and human resources.

Rapid advances in technology make scientific and engineering equipment obsolete at an ever increasing rate. Equipping laboratories capable of advanced, state-of-the-art research is becoming increasingly expensive. Estimated cost for minimum refurbishment of the top 100 U.S. research universities is $\$ 2$ billion-not to mention increased cost of operation, maintenance and five year replacement cycle.

The availability of talent capable of conducting state-ofthe-art research is subject to the same pressures. The proliferation of technical information and staying current in one's field is an ever present challenge. In fields that are already experiencing shortages, this creates an additional challenge to keep available talent from becoming obsolete.

The availability of limited talent, as well as scarce financial resources, make it ill advised for industry, universities or government to try to "go it alone" for excellence. For America to regain its industrial vitality and reaffirm its technological leadership, we must find ways to integrate the efforts among universities, industry, and government. Collaborative efforts are no longer just an alternative, but they have become a necessity.

When the North Carolina Microelectronics initiative was established in 1980, we recognized that we would need to take advantage of all of the resources available in North Carolina to develop a true "center of excellence." Before the Center was created, each of our participating universities hoped to develop its own major microelectronics program. But none could afford nor manage a comprehensive microelectronics program alone.
But, like every other state, North Carolina has only limited resources for the development of research and educational excellence. The research universities in North Carolina had been talking about a microelectronics program for a number of years, but there were not sufficient resources available. Each university wanted to develop its own major program; they were each considering a whole program, not just a part of one. Working together was the only way they could develop a total world class program.

Now, each professional school will benefit from the others by the sharing of modern equipment, world class facilities, and first rate staff.

The development of world class capability in any technology is ultimately dependent on human resources. Our six participating institutions-Duke, North Carolina State, University of North Carolina-Chapel Hill, North Carolina A\&T, UNC-Charlotte and the Research Triangle Institute-plus the new Center itself, allow for the development of a critical mass of professional talent in microelectronics-currently about 150-that could not be developed individually: and that has occurred in just three years. I might add that this new program has attracted over 30 new faculty from industry.

The cost of world class programs requires new and bold partnerships in order to accumulate the resources and talent necessary for success. The North Carolina Microelectronics program has provided about $\$ 50$ million for the development and joint sharing of new technical facilities and talent as a solid commitment of the three sectors of government, education and business.

In recent years we also have seen a number of other collaborative efforts between and among universities, industry, and government.

There are now approximately 20 university-based programs which have combined the efforts of industry, universities, and government to varying degrees. The

\section{Continued U.S. Leadership In Electronics Requires Improved Management of Technology Transfer}

semiconductor industry has taken the initiative by jointly funding the Semiconductor Research Corporation or SRC. This collaborative effort is supported by 23 companies in the semiconductor industry and is currently sponsoring research in 30 private and public universities. The objective here is to encourage and influence a more coherent direction to university-based research for the semiconductor industry. The most recent new initiative is the Microelectronics and Computer Technology Corporation, or MCC. Thirteen shareholder companies that compete in the computer and semiconductor markets are providing funds and personnel to 
this joint effort. The objective in this case is to maintain an ability to compete. This technology is one where the $\mathrm{R} \& \mathrm{D}$ resources required are too costly, or too thin, for individual companies to take care of their own need-an unusual solution to a new problem. But think of the implications of this approach for all of the smaller companies who cannot afford the cost of participation in MCC. Will they be locked out of future competition with current MCC companies?

But, these types of efforts alone are not enough. While we have progressed substantially from the parochial, protective attitudes of the past, exploration of additional mechanisms for ensuring that knowledge is generally transferred into useful technology in a timely manner is a fundamental requirement.

The challenge before us requires new and creative bold actions; to manage scarce human capital resources; to avoid dissipating precious resources with unproductive duplication or unfocused efforts.

\section{Roles for Members of the Coalition}

New initiatives will require more commitment and collaboration among government, industry, and universities. The task of technological leadership is too great and the stakes are too high not to make the best use of the resources available.

The importance of technologies such as microelectronics to our national economy, as well as defense and security, makes it imperative that the Federal government continue to support microelectronics education and research efforts. However, it is just-as evident that leadership and resources will also need to come from other members of the coalition-state and local governments, universities, and industry. The Federal government does not have unlimited resources and, like it or not, the new federalism is at work.

To me this is not an unwelcome development. While the Federal government needs to provide strategic support to microelectronics education and research because it is a national issue in which the Federal government has a vested interest, problems cannot be solved just through Federal funding. Initiatives in microelectronics require both innovative leadership and broader genuine support. Both are easier to obtain with programs of manageable size, with non-bureaucratic organizations that are not bound by red tape and can easily evolve to meet continually changing requirements.

Fortunately, progressive leadership in some state governments recognizes the need to take new aggressive initiatives for the renewal of economic development and growth in their states and region.

The resources available to address the challenge before us requires that investments be made not to achieve me-too mediocre programs, but programs of excellence that contribute not only to state and regional goals but national goals as well. Universities must also make a realistic assessment of how they can best contribute. Not every university can become a center of excellence in every field. Efforts need to be focused on already established strengths.
It is estimated that over 50 percent of all basic research is conducted in universities. In order to meet the challenge before us, it is critical that basic knowledge obtained through this research be translated and transferred more effectively into useful technology.

Industry is developing an ever increasing role in supporting the education and research in our universities. This support in some cases may be perceived to be social responsibility, but from a pragmatic view industry is recognizing more and more the critical contributions the universities can make to their business.

In 1981 industry funded $\$ 240$ million of university R \& D. However, that was only three percent to four percent of all university R \& D. Industry clearly recognizes that the . continuing flow of talent from our universities, as well as basic knowledge that can be translated into useful technology, is essential to long-term industrial economic growth.

Recognizing some of the fundamental roles of government, universities, and industry, I would like to outline some of the basic requirements that can serve as a guide in the further development of modern technologies such as microelectronics.

\section{Requirements for a Successful Initiative}

Programs must be structured so they are able to achieve maximum useful results. This may require the establishment of new linkages, as well as the strengthening of existing relationships. A major overriding concern should be to avoid solo and non-integrated, less than critical mass, efforts.

With this as a general criteria, I would like to identify what I believe are some of the basic requirements for further progress in coalitions that can make a national difference.

1. The first is the need for a long-term, strategic approach to substantial funding. This includes taking advantage of existing programs and investments. These programs are probably best positioned to meet complex technical challenges and will tend to inhibit duplication. It is also necessary to obtain significant funding, at least on a threeyear basis, from all members of the coalition as a dependable commitment to tough common goals. 2. Secondly, it is essential to structure in-depth interaction among the limited talent available. Full participation by personnel from industry, universities, and government is necessary for understanding each other's perspective and for crystallizing and mutually accepting responsibility for important common goals. The program structure should encourage participants from each of the several coalition organizations to work side by side in a common facility for the most effective results in the long term. This intimate involvement also can be used to structure the interdisciplinary approaches required by the complexities of today's research.

3. Since technological and economic leadership are the first objectives for the new coalitions being discussed, the third and last principle is to consciously structure for improved 
and realistic technology transfer and R \& D in progressively more scientific endeavors; this strongly suggests that we make use of all basic related investments. Technology developed for defense purposes needs to be consciously transferred to the commercial sector, and vice versa. This need suggests that some coordinated efforts and common basic programs are desirable to facilitate the more timely translation of the enormous defense $\mathrm{R} \& \mathrm{D}$ expenditure to the non-defense industry-at least in the basic technologies such as next generation sub-micron integrated circuits.

Having identified the need for realistic funding, direct coalition involvement and the objectives of technology transfer, I would like to relate to you how the Microelectronics Center of North Carolina is positioned to meet these requirements to serve as a facilitator between members of the coalition to address the complex challenges of technical excellence and international economic leadership.

The Microelectronics Center of North Carolina is a results-oriented, non-profit corporation that serves as a neutral industrial research center where all parties addressing the future of microelectronics can work together to meet the technical challenges that lie between basic research and manufacturing reality.

In creating this Center, we anticipated and solved up front many of the challenges. For instance, representatives of all participants in the $\mathrm{R} \& \mathrm{D}$ process physically work within our research complex. This includes the Center's permanent staff, specialists with joint university and Center appointments, scientists and engineers representing industrial affiliates, visiting scientists from other national centers, and graduate students engaged in special projects.

This total-capability Center is, to the best of our knowledge, the world's only neutral microelectronics manufacturing research complex where next generation sub-micron processes, materials and fabrication equipment can be simultaneously developed and evaluated under realuse conditions. The program is structured so that there are no "disconnects" as projects move from research to design to prototype fabrication. Communications channels are always open. New developments can be shared on a timely basis.

Also, we have addressed and eliminated potential sources of conflict between industrial affiliates and our participating institutions. All parties understand from the outset what will happen when affiliate-sponsored pooled research yields inventions. Affiliates have a defined temporal advantage in the use of intellectual properties on a preferred-royalty basis. Residual royalty income will be reinvested in new affiliate research projects. This business-like arrangement is fair and profitable to all involved.

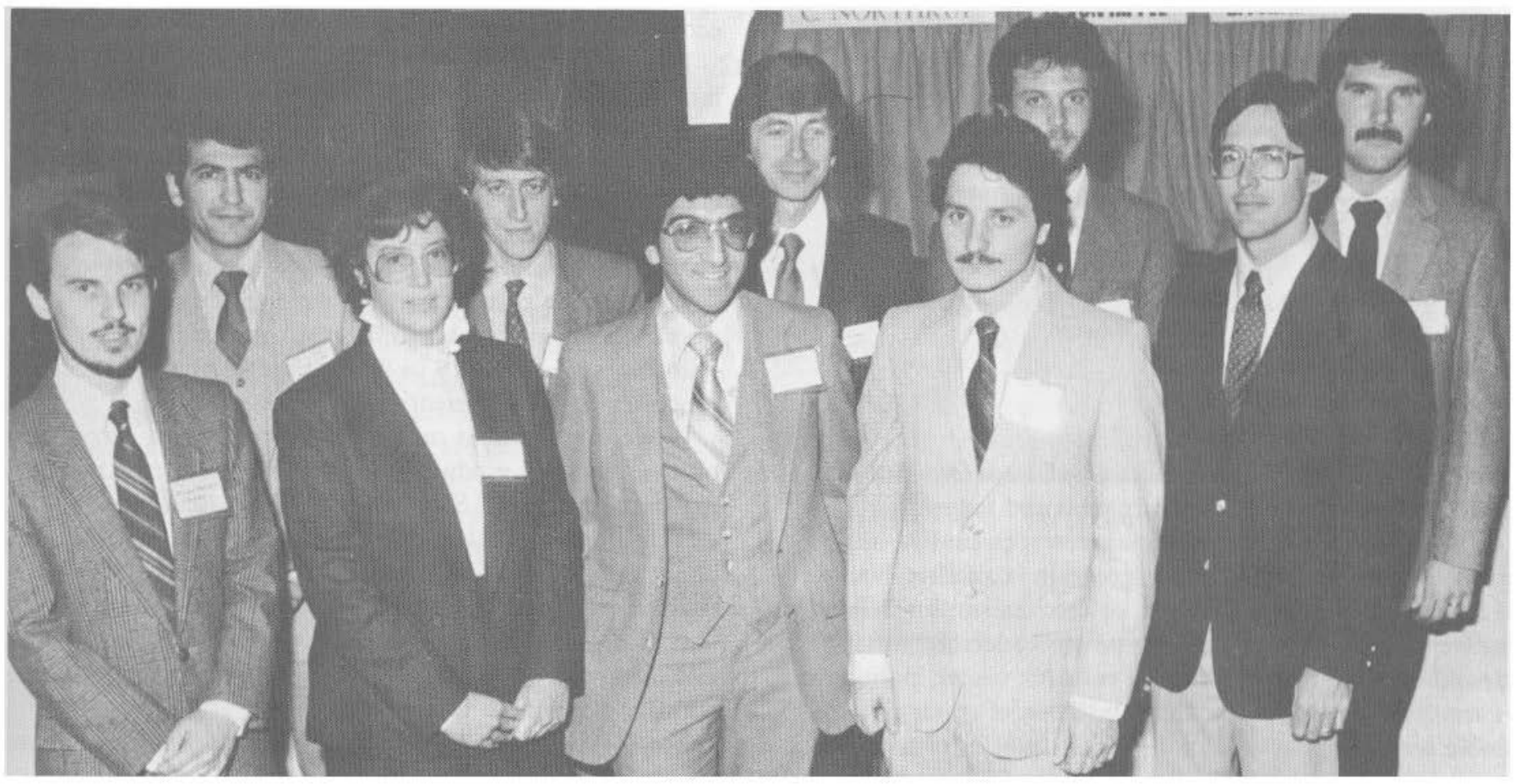

STUDENT AWARDS
STUDENT AWARD WINNERS: Receiving special recognition at the Annual Meeting were the 10 MRS Student Award winners (rear, left to right) L. Yasser Kahlil, Penn State; Luc Baufay, University de l'Etat Mons; Jerzy H. Mazur, Berkeley; P.J. Burnett, Cambridge; Calvin H. Carter, N.C. State. (Front, left to right) Phillipe Fauchet, Stanford; Karen J. Morrissey, Cornell; Michael J. Aziz, Harvard; Joseph A. Stroscio, Cornell; Timothy Sands, Berkeley 
Both research and education involving the full spectrum of microelectronics disciplines and technologies form the framework of the North Carolina program.

The participating institutions place strong emphasis on the practical value of their educational and research programs. The "Center" concept depends on and utilizes the talents of sixteen technical departments at these first-class universities to develop the scientific and engineering resources for the future and to conduct state-of-the-art research. For example, this interdisciplinary approach includes 62 faculty in electronics materials-just about half of the total of 133 materials faculty in our Participating Institutions. That is, $\mathrm{G}_{2}$ faculty and staff are involved in work in electronic materials including 10 research programs in materials properties and seven programs in materials modification. concentrated microelectronics resource of over 150 professionals. We are also now putting in place a dedicated 150 mile, \$6.5 million television and data communication network for shared teleclassing, research and VLSI design in order to make the consortium real and functionally effective.

New centers such as ours can provide a vertically integrated $\mathrm{R} \& \mathrm{D}$ effort from materials and devices to manufacturing and system applications that is available to government, other centers, and industry alike. In neutral facilities, such as this, engineers and scientists can work together in all fundamental areas for technology transfer to industry in a coherent and non-fragmented way.

New centers such as this will also be able to assist the Federal government and other centers in getting their technology advances translated into industrial level

\section{It Is Time Now At The National Level To Take Full Advantage Of The Investments And Program Results From Existing Initiatives}

Our new Center is a world-class, neutral manufacturing/research laboratory where semiconductor manufacturers, systems companies, suppliers, integrated circuits users, and university researchers can work together to convert ideas to commercial technology.

\section{A Successful Program for Technology Transfer}

It is time now at the national level to take full advantage of the investments and program results from existing initiatives. Advances in knowledge and specific development of technologies for narrow purposes may not be enough to keep the United States cast in the leadership role.

I referred earlier to the 20 Centers for microelectronics that are university based; add to that the scores of NSF and DARPA efforts and the numerous government electronics labs, and it is clear that there already is a substantial level of national resources in the field of modern electronics.

What we need now are some new mechanisms that will help coordinate, focus and expedite the translation of knowledge being developed by this enormous set of resources into usable technology for both government and industry.

Like the set of national materials research centers being established, the North Carolina program is another example of a new national level coalition, or mechanism, for helping resolve the issue of national technology leadership: a full capability neutral manufacturing research center, positioned to serve as a facilitator for the translation of research into usable technology as well as the direct transfer of technology to industry.

We believe the North Carolina Microelectronics Program can serve as a new national model. Primarily state funded with some $\$ 43$ million in direct grants to date, we are now occupying a new, from-the-ground-up, $\$ 30$ million world class sub-micron design and fabrication facility, and are building a first class industrial research staff to enhance and work with the very substantial faculty for a total developments in a more timely way.

Let me conclude by saying that the North Carolina program is just one example of what can be done with effective top-down leadership-leadership by government, university and industry chief executive officers with strategic vision and a creative but realistic approach to serious economic and technology issues.

The challenge before us is, however, not to just establish large new programs, but is to implement practical new ways of working together, establishing substantial programs that encourage and expedite truly effective technology transfer and not just half-way, me-too efforts.

I am confident that we have the national resources to achieve and maintain an international leadership role.

We have the capability of harnessing new technology developments as they occur, of making sure there are no "disconnects" as we try to develop useful products and processes from new scientific knowledge.

While other nations may be investing greater percentages of gross national product in R \& D efforts, the fact of the matter is that the U.S. invest more absolute dollars in research that any other country. And there's little debate about the quality of this research. So our perhaps key problem is in fact effective technology transfer.

If so, the United States must selectively develop creative and adequately funded national initiatives for the timely transfer of research to industry.

But if states take the responsibility for filling this national void of supporting a new federalism, it is entirely appropriate for federal appreciation of such efforts.

This means an understanding of the opportunity for sharing enhanced support of new initiatives. Such support will also encourage the state legislatures to continue their support to mutually ensure the development of national level technology transfer resources at the state level.

Thank you. 